This item was submitted to Loughborough's Research Repository by the author.

Items in Figshare are protected by copyright, with all rights reserved, unless otherwise indicated.

\title{
Effect of an intense period of competition on race performance and self- reported illness in elite cross-country skiers.
}

PLEASE CITE THE PUBLISHED VERSION

http://dx.doi.org/10.1111/sms.12452

\section{PUBLISHER}

(c) John Wiley \& Sons A/S.

\section{VERSION}

AM (Accepted Manuscript)

\section{PUBLISHER STATEMENT}

This work is made available according to the conditions of the Creative Commons Attribution-NonCommercialNoDerivatives 4.0 International (CC BY-NC-ND 4.0) licence. Full details of this licence are available at: https://creativecommons.org/licenses/by-nc-nd/4.0/

\section{LICENCE}

CC BY-NC-ND 4.0

\section{REPOSITORY RECORD}

Gleeson, Michael, Ida S. Svendsen, Thomas A. Haugen, and Espen Tonnessen. 2019. "Effect of an Intense Period of Competition on Race Performance and Self-reported Illness in Elite Cross-country Skiers.". figshare. https://hdl.handle.net/2134/16967. 


\section{Effect of an intense period of competition on race performance and self-reported illness in elite cross-country skiers.}

Illness and performance after Tour de Ski

Ida S. Svendsen ${ }^{1}$, Michael Gleeson ${ }^{1}$, Thomas A. Haugen ${ }^{2}$, Espen Tønnessen ${ }^{2}$

1) School of Sport, Exercise and Health Sciences, Loughborough University, UK.

2) Norwegian Olympic and Paralympic Committee and Confederation of Sports, Oslo, Norway

"This manuscript has been read and approved by all the listed co-authors. This manuscript is original and not previously published, nor is it being considered elsewhere until a decision is made as to its acceptability by the SJMSS Editorial Review Board."

Abstract word count: 200

Text word count: 4018

\section{Address for Correspondence:}

Ida S. Svendsen

School of Sport, Exercise and Health Sciences,

Loughborough University,

Leicestershire, UK.

LE11 3TU.

E-mail: i.s.svendsen@lboro.ac.uk

Telephone +447794904859

Key words: endurance athletes, upper-respiratory illness, overreaching, training load. 


\begin{abstract}
Aim: To determine whether participating in a cross-country skiing stage race (TDS) affects subsequent illness incidence, training and race performance. Methods: Selfreported training and illness data from 44 male and female elite cross-country skiers were included. In total, 125 years’ of data was collected (2-3 seasons per athlete). Illness incidence, training load and performance in international competitions were calculated for athletes who did and did not participate in TDS. Results: $48 \%$ of athletes reported becoming ill during or in the days immediately after taking part in TDS, vs. 16\% of athletes who did not participate. In both groups, illness incidence was somewhat lower for female athletes. For male athletes, race performance was significantly worse for 6 weeks following TDS vs. 6 weeks before TDS. Furthermore, while female athletes who participated in TDS performed relatively better than controls in Olympics/World Championships, male athletes who participated in TDS typically performed worse in subsequent major championships. Conclusion: Participating in TDS appears to result in 3-fold increase in risk of illness in this period. Male athletes appear more prone to illness and also see a drop in race performance following TDS, possibly linked to differences in training load before and after the event.
\end{abstract}




\section{INTRODUCTION}

To reach an internationally elite level in any sport requires a huge amount of training. Consequently, athletes are frequently treading a fine line between the optimal training load to stimulate performance adaptation, and excessive overload leading to maladaptive outcomes (Meeusen et al., 2006). Dependent on the characteristics of the sport, it has been reported that elite endurance athletes train between 500 hours (e.g. long distance running) (Billat et al., 2001; 2003) to well in excess of 1000 hours per year (e.g. triathlon, cycling, swimming, rowing) (Schumacher \& Mueller, 2002; Fiskerstrand \& Seiler, 2004; Zapico et al., 2007; Gao, 2008; Guellich et al., 2009; Neal et al., 2011) with elite cross-country skiers typically training $~ 800$ hours per year, of which $>90 \%$ is endurance training (Tønnessen et al., 2014a). Previous studies suggest that intense periods of training and competition may result in adverse changes to a number of immune variables (Baj et al., 1994; Mackinnon and Hooper, 1994; Gleeson et al., 1995; Halson et al., 2003; Lancaster et al., 2004; Meyer et al., 2004; Coutts et al., 2007; Robson-Ansley et al., 2007; Morgado et al., 2012). This in turn appears to lead to an increased susceptibility to opportunistic infections, in particular upper-respiratory tract infections such as colds and influenza (Nieman, 2000). However, limited data exist on the effects of intensified periods of competition on illness incidence in world-class endurance athletes already training in excess of 700 hours per year.

The Tour de Ski is an event that has been part of the XC skiing calendar every year since its introduction by the International Ski Federation (FIS) in 2006. The race consists of six to nine stages during late December and early January. These stages are held in the Czech Republic, Germany, Italy, and Switzerland, with the competition typically running over an eight to eleven day period, including one or two rest days. For those athletes that take part, it undoubtedly represents the most intense period of competition of the season. Not only are competitors required to push their bodies to the physical limit on multiple consecutive days, but they are also exposed to the additional stressors of travel, cold temperatures (typically ranging from $+4^{\circ} \mathrm{C}$ to $-10^{\circ} \mathrm{C}$ ) and moderate altitude (1000-1300 m above sea level), as well as the repeated psychological pressure of competition. Stage races such as this provide a unique opportunity to examine the impact of short-term overreaching in elite athletes, something which is 
often not feasible or achievable in a laboratory setting. It seems conceivable that taking part in a stage race such as Tour de Ski could have an immunodepressive effect, resulting in increased illness incidence during both the competition period itself, and in the days that follow. Indeed, anecdotal reports from athletes and coaches suggest that this may well be the case, although no empirical evidence is currently available.

Furthermore, a large number of elite cross-country skiers choose to take part in Tour de Ski in the same year that they also participate in Olympic Games or World Championships. Recent studies have examined the training and peaking practices of elite athletes leading up to major championships, and underlined the importance of an appropriate training volume and intensity distribution (Tønnessen et al., 2014a; 2014b). These studies also found that competitions are a key component in an athlete's preparation for a major championship, making up a substantial proportion of all highintensity training in this period. However, it is not known whether a stage race such as Tour de Ski, characterized by a marked shift in the normal intensity distribution towards more high-intensity activity (of which all is performed as competitions rather than interval training) and relatively little low-intensity training, could affect subsequent training and race performance. It is possible that taking part in such an event could impair an athlete's ability to achieve peak performance in major championships 5-7 weeks later, or even lead to a state of non-functional overreaching or overtraining (Meeusen et al., 2006). On the other hand, it is equally conceivable that taking part in Tour de Ski might in fact play a beneficial role in the preparation process of these athletes.

Hence, the aims of the current study were to determine, 1) whether athletes experience increased illness during and in the days immediately after taking part in Tour de Ski, compared to those athletes who do not take part in Tour de Ski, 2) whether taking part in Tour de Ski affects subsequent training and race performance, particularly in major championships (Olympic Games and FIS Nordic Ski World Championships), and 3) whether any of these effects are influenced by sex.

\section{METHODS}

\section{Subjects}


Self-reported training and illness data from 27 male and 17 female elite cross-country skiers were included in the current study. In total, 127 years' worth of data was collected, typically consisting of 2-3 seasons per athlete from 2006-2014 (Table 1). Of the data collected, 10 seasons were excluded due to inadequate detail in the recording of either training or illness, or due to periods of missing data. A further two seasons were excluded as outliers due to the athletes experiencing repeated and unusually prolonged episodes of illness, resulting in the annual number of illness days being far above $(>3$ SDs) the group mean. Of the remaining 115 seasons, 42 included participation in Tour de Ski. In total, data for 38,525 days were collected, including 380 episodes of illness and 86,739 hours of training.

(Table 1 here)

Inclusion criteria were 1) currently, or during the analysed time period, selected to represent the Norwegian national senior or recruit team for cross country skiing, 2) over 18 years of age, and 3) had systematically and in sufficient detail recorded their day-today training from junior through to senior level. In total, these athletes had won 106 World Championship and Olympic medals (individual and relay events). The regional ethics committee of Southern Norway reviewed the study and concluded that, due to the nature of the investigation, it did not require their approval. The study was therefore submitted to and approved by the Norwegian Data Protection Authority (NSD), and all athletes gave their oral and written informed consent for their data to be included in the study.

\section{Training monitoring}

Athletes included in the study recorded their day-to-day training across the entire year in Microsoft Excel training diaries designed by the Norwegian Ski Federation or, since 2012, in the digital version developed by the Norwegian Olympic Federation (www.oltdagbok.net). The training recorded for each session included total training time distributed across training type (strength, endurance, sprint, etc.), activity mode (skiing, roller-skiing, running, cycling etc.), and intensity zone (Table 2). In addition each session included a "comments” field where athletes recorded, amongst other things, race 
results, additional details regarding each training session (sets, repetitions etc.), illness symptoms, whether training was discontinued or modified due to illness or injury, competitions, days of travel and days spent at altitude ( $\geq 1500 \mathrm{~m}$ above sea level).

(Table 2 here)

\section{Illness incidence}

Based on the definitions proposed by Matthews et al. (2010) self-reported illness was categorized as either "severe", where an athlete reported symptoms indicative of infectious illness AND training was discontinued, or “moderate” where an athlete reported symptoms but continued to do some form of training. An illness episode was defined as a subject reporting "moderate" symptoms on two or more consecutive days, or "severe" symptoms on at least one day. Where athletes reported allergies, asthma, or gastrointestinal distress due to training/nutrition practices, these were not included in the analysis. Only symptoms likely to be due to opportunistic infection were retained for analysis. These included symptoms of upper respiratory infections (blocked or runny nose, sore throat, sneezing), lower respiratory infections (coughing, sputum, chest congestion, wheezing, fever) and gastrointestinal infections (nausea, vomiting, diarrhoea, abdominal pain).

To determine whether taking part in this event might increases the risk of illness, the number of athletes that experienced an episode of illness either during, or within 10 days after completion of the Tour de Ski, was calculated. The percentage of athletes that became ill during Tour de Ski or in the ten days immediately after taking part in Tour de Ski was then compared to the percentage of athletes who did not compete in Tour de Ski and who became ill in the same time period (control).

\section{Training load}

To determine whether taking part in Tour de Ski resulted in a significant increase in exercise load above "normal” and whether taking part would impact on subsequent training, average daily training impulse (TRIMP) (Banister \& Calvert, 1980) was determined for 6 weeks immediately before Tour de Ski, during Tour de Ski (including races, warm-ups, cool downs and training on rest days), and for 6 weeks after Tour de 
Ski. This was calculated by multiplying duration in minutes by the intensity zone (1-5; Table 2) reported in the training diaries. TRIMP values, total race time and distance covered during Tour de Ski were also compared between the sexes.

\section{Race performance}

In addition, to determine whether participation in Tour de Ski might have an impact on subsequent race performance, average FIS points and placing per race, and best placing were determined for the 6 weeks immediately before Tour de Ski and 6 weeks immediately after Tour de Ski for both males and females for the TDS group and a matched control group (CON). This 6-week time-frame was chosen as it typically represents the race period between Tour de Ski and that season's major championships (World Championships/Winter Olympic Games), while also being long enough to include a minimum of one World Cup race for every athlete. Where possible, a different season for the same athlete was used as the control. In the small number of cases where this was not possible (i.e. an athlete had competed in Tour de Ski in all available seasons), control athletes were matched as closely as possible based on sex, age, discipline and performance level. Only international competitions were included in these analyses (World Cup, World Championship and Olympic races), and only performance in each athlete's own discipline (i.e. sprint races for sprint skiers, distance races for distance skiers). Results were taken from the FIS website (www.fisski.com/cross-country/). FIS points were calculated using the following formula: $(\mathbf{F} \cdot \mathbf{T x}) / \mathbf{T o}-\mathbf{F}$

Where: F= FIS Factor (800 for interval starts, 1200 for sprints / pursuits with a break, 1400 for mass starts and pursuits without a break); $\mathbf{T} \mathbf{x}=$ competitor's race time in seconds; To = winner's race time in seconds.

In addition, to determine whether taking part in Tour de Ski might adversely affect an athlete’s subsequent performance in Olympic Games or World Championships 1-2 months later, placing in these events was compared for both males and females for TDS and CON. In order to account for differences in performance level and indicate whether or not the athletes were able to reach peak performance at this time, placing in World Championships/Olympic Games were normalised as a percentage of each athlete’s 
mean placing in international competition for that whole season. For example, where an athlete's mean result for the season was $9^{\text {th }}$, and they finished $6^{\text {th }}$ in the Olympic Games, this was expressed as $66.7 \%$.

\section{Statistical analyses}

Normally distributed data are presented as mean with standard deviation (SD). Data that were not normally distributed data were treated using a Box-Cox transformation (Box \& Cox, 1964) prior to analysis, and are presented as back transformed geometric mean \pm 95\% confidence interval (CI). Data were analysed using an independent or mixed-model analysis of variance with a Bonferroni post-hoc correction. Differences in total race time and total race distance between men and women were analysed using an independent samples T-test. Significance was accepted at the $\mathrm{p}<0.05$ level.

\section{RESULTS}

\section{Training and competition load}

Taking part in Tour de Ski resulted in a significant increase in average daily TRIMP compared to 6 weeks before Tour de Ski for both men (203 \pm 28 vs. $160 \pm 15)$ and women (205 \pm 18 vs. $177 \pm 14)(\mathrm{p}<0.01$, Figure 1). The female athletes had significantly higher training loads than the male athletes both 6 weeks before (177 \pm 14 vs. $160 \pm 15, \mathrm{p}<0.01)$ and 6 weeks after Tour de Ski (164 \pm 14 vs. $128 \pm 30, \mathrm{p}<0.01)$, but there was no sex-difference in TRIMP during the competition period itself. However, total Tour de Ski competition time was significantly higher for men than women (246 \pm 40 vs. $170 \pm 21 \mathrm{~min}, \mathrm{p}<0.001$ ), as was total Tour de Ski race distance (101 \pm 6 vs. $59 \pm 4$ km, $\mathrm{p}<0.001)$ (Figure 2, panels $A \& B)$.

(Figure 1 here)

(Figure 2 here)

\section{Illness incidence}


In 20 / 42 (48\%) seasons which included participation in Tour de Ski, athletes reported becoming ill during or in the first 10 days immediately after the competition. Only 12 / 73 (16 \%) of the athletes who did not take part in Tour de Ski reported becoming ill in the same time period (Figure 3). Out of the 20 episodes of illness reported, $85 \%$ were symptoms indicative of upper respiratory infection (sore throat, blocked/runny nose, coughing, sneezing, headache, fever). When comparing men and women separately, a larger proportion of the male athletes, both in the TDS (53\% vs. 44\%) and CON (21\% vs. 8\%) groups, became ill in this time period compared to the female athletes (Figure $3)$.

(Figure 3 here)

\section{Race Performance}

There was no significant change in race performance in the 6 weeks following Tour de Ski for female athletes. However, for the male athletes, average placing in international races was significantly worse following participation in Tour de Ski (Figure 4), increasing from $9^{\text {th }}\left(95 \%\right.$ CI: $\left.6^{\text {th }}-15^{\text {th }}\right)$ to $18^{\text {th }}\left(95 \%\right.$ CI: $\left.14^{\text {th }}-23^{\text {rd }}\right)$ with no significant change in CON (Interaction effect: $F(1,34)=9.884$, $p=0.003$ ). Similarly, best placing achieved in international competition was significantly worse for the 6 weeks after taking part in Tour de Ski compared to the 6 weeks before (Figure 5), going from $3^{\text {rd }}$ (95\% CI: $\left.2^{\text {nd }}-6^{\text {th }}\right)$ to $10^{\text {th }}\left(95 \%\right.$ CI: $\left.14^{\text {th }}-23^{\text {rd }}\right)$, despite no significant change in CON (Interaction effect: $\mathrm{F}(1,34)=5.130, \mathrm{p}=0.03$ ). There was also a borderline significant effect for average FIS points per race (Interaction effect: $F(1,26)=4.152$, $\mathrm{p}=0.05$ ). Despite no change in CON, pairwise comparisons showed that average FIS points per race went up significantly in the TDS group ( $\mathrm{p}=0.007)$ from 13 (95\% CI: 9.1-17.5) to 22 (95\% CI: 16.1-28.9), a difference equivalent to skiing 26 seconds slower in a $15 \mathrm{~km}$ classic style race.

(Figure 4 here)

(Figure 5 here) 
Finally, there was a significant interaction effect when examining performance in World Championship and Olympic Games for men and women who took part in Tour de Ski compared to $\operatorname{CON}(\mathrm{F}(1,49)=4.187, \mathrm{p}=0.046)$. While female athletes who took part in TDS typically performed relatively better in these major championships compared to CON, male athletes who took part in Tour de Ski typically performed worse in Olympic/World Championships than CON (Figure 6).

(Figure 6 here)

\section{DISCUSSION}

To the authors' knowledge, this is the first study to investigate the effects of an intense period of repeated competition on subsequent illness incidence, training and race performance in a large cohort of world-class winter sports athletes. A main finding of this study is that athletes taking part in a cross-country skiing stage race resulting in a significant increase above normal training load, had a 3-fold higher risk of contracting an illness during and in the days immediately after the competition, compared to control athletes, with male athletes in both groups appearing somewhat more susceptible to illness than female athletes. Another major finding is that male athletes typically see a drop in race performance for at least 6 weeks following participation in Tour de Ski, alongside a concurrent reduction in training load.

The finding of increased illness following participation in Tour de Ski is in accordance with previous studies reporting a relationship between upper respiratory illness (URI) risk and a high level of exercise stress (Nieman, 1994; Moreira et al., 2009; Gleeson et al., 2011). The results also support earlier findings that URIs are the most common medical complaint affecting athletes (Reeser et al., 2003; Fricker et al., 2005), with 17 / 20 cases reported following Tour de Ski being symptomatic of URI. However, it is worth bearing in mind that the observed increase in illness could also be due to factors in addition to the physiological stress of the competition itself. For example, it is 
possible that athletes may have had a higher-than-normal exposure to pathogens due to increased contact with crowds and media during the competition period.

Compared to female athletes, a greater proportion of male athletes reported becoming ill, in both the TDS and CON groups (30\% of all male athletes vs. $25 \%$ of all female athletes). This difference does not appear to be explained by differences in absolute training load, since there was no significant difference in TRIMP between males and females during the race period. However, because the male athletes had a lower baseline training load going into the race, the increase in TRIMP as a result of taking part in Tour de Ski was greater (27\% increase in TRIMP compared to $16 \%$ for the female athletes). Furthermore, evidence suggests that men typically have a somewhat lower immune response than women, and therefore may be more susceptible to opportunistic infections such as colds and influenza (Engler et al., 2008), possibly due to an immunosuppressive effect of testosterone (Furman et al., 2014). On the other hand, in contrast to the general population, data from medical reports following major sporting events such as the Olympic Games have generally found a higher incidence of illness among female compared to male athletes (Engebretsen, et al., 2010; 2013; He et al., 2014), which does not correspond with the findings of the current study.

The male athletes experienced a significant drop in performance in international races in the 6 weeks following participation in Tour de Ski, while there was no change for female athletes. Furthermore, male athletes typically performed relatively worse in World Championships and Olympic Games after taking part in Tour de Ski in the same season ( 5-7 weeks earlier), while female athletes typically performed somewhat better following Tour de Ski participation. This is likely, at least in part, due to a marked (20\%) reduction in training load for the men after compared to before Tour de Ski, while the female athletes appear better able to recover and maintain a similar training load in the weeks following the race. The reduction in TRIMP observed for the men from before to after Tour de Ski is equivalent to 3.7 hours less per week of low-intensity training (zone 1), or 56 minutes less per week of high-intensity training (zone 4). It is possible that such a reduction in training stimulus could impact negatively on the resulting physiological adaptation and thereby explain the drop in race performance. It is interesting that the male athletes had a significantly lower training load going into Tour 
de Ski, so that the increase in training load above baseline during Tour de Ski was greater for the male athletes than it was for the female athletes. This may have increased the risk of Tour de Ski participation leading to non-functional overreaching or even overtraining in the male athletes (Meeusen et al., 2006), and may help to explain why they were subsequently unable to maintain their normal training load after the competition.

As well as differences in training load before and after the event, the observed sex differences in subsequent race performance may be partly explained by greater competition load in men's compared to women's Tour de Ski. The total race distance for the men is $\sim 71 \%$ further than in women's Tour de Ski, with each stage typically being substantially longer. Similarly, total competition time is $\sim 46 \%$ longer for the men. However, it is interesting that this did not result in a significant difference in TRIMP, due to the female athletes typically engaging in markedly more low-intensity physical activity around and between races (e.g. longer warm-ups and cool-downs), and more easy training on the rest days during Tour de Ski. Another possible explanation for the drop in performance observed for the male, but not the female athletes, is that there are a greater number of male athletes competing at the very top end of cross-country skiing. Hence, the time differences between places is typically smaller, and a reduction in performance resulting in a small time decrement can mean a loss of a greater number of places compared to the women's elite races where the time differences between competitors are typically larger. For example, for the last three Olympic Games, the average time difference between $1^{\text {st }}$ and $20^{\text {th }}$ position in the men's $50 \mathrm{~km}$ event was 47 seconds, compared to an average time difference of 3:32min between $1^{\text {st }}$ and $20^{\text {th }}$ position in the equivalent women's $30 \mathrm{~km}$ event.

As a greater proportion of the male athletes reported illness during and following Tour de Ski this may also have affected their subsequent performance, due to loss of training days during this time. A final explanation could be that a greater proportion of top level female cross-country skiers choose to take part in Tour de Ski, and that any absolute performance decrements are therefore not reflected in race positions or FIS points, because the majority of the other competitors have been similarly affected. For example, of the 19 athletes who came top 10 in the three women's individual XC distance events 
in the 2014 Olympic Games (10 km classical, 15 km skiathlon, $30 \mathrm{~km}$ freestyle), 68\% had participated in Tour de Ski earlier in the same season. Of the men, only $38 \%$ of the athletes who claimed the top ten places in the individual XC distance events (15 km classical, $30 \mathrm{~km}$ skiathlon, $50 \mathrm{~km}$ freestyle) had also competed in Tour de Ski in the same season.

A strength of this current study is that it includes a considerable amount of data for a large cohort of world-class endurance athletes. However, because the data are based on athlete self-report, and illness episodes were therefore not verified by a medical professional, it is not possible to ascertain whether the symptoms reported were truly due to an infection. Indeed, Spence et al. (2007) found that pathogens were isolated in fewer than $30 \%$ of symptomatic URI cases in elite triathletes, suggesting that a large proportion may be due to non-infectious causes. Similar concerns may be raised regarding the accuracy of the training data. However, Sylta et al. (2014) concluded that elite endurance athletes report their training accurately. The same level of accuracy and validity likely holds true for this data set, as both athlete groups used similar reporting routines and a number of the athletes are, in fact, included in both papers. In addition, athletes recorded both their training and illness symptoms on a daily basis, which likely reduced reporting error. It should be recognised that the analysis method used in the current study, based on seasons rather than individuals, is susceptible to the influence of a small number of outliers. However, all of the individuals included in the current study were part of the Norwegian national team and therefore represent a highly homogenous group of elite athletes. During the analysed time period, cross-country skiing training culture in Norway has changed very little. Hence, both inter- and intra-individual differences between seasons in terms of training variables are small, and outliers with abnormal annual illness rates were excluded from the analyses.

Taking part in an 8-11 day XC skiing stage race appears to result in a 3-fold increase in the risk of contracting an illness, primarily URI, in this period. Whether taking part in the competition or not, male athletes appear somewhat more prone to illness than female athletes. Furthermore, unlike their female counterparts, male athletes see a drop in race performance for at least 6 weeks following participation in Tour de Ski, possibly due to suboptimal training loads going into and coming out of the event. Male athletes also 
typically perform worse in subsequent World Championships / Olympic Games when taking part in Tour de Ski earlier in the season. Female athletes, on the other hand, appear to perform somewhat better after participating in Tour de Ski.

\section{PERSPECTIVES}

In accordance with previous studies linking training load and infection susceptibility, this study provides evidence that an intense period of competition leads to increased illness incidence, even in elite athlete populations who already have an extremely high training load. The study also provides new insight into how participation in such an event might influence subsequent training and race performance. This information can aid in making an informed decision about whether or not an athlete should take part in a competition such as Tour de Ski in the same season that they are also aiming to reach peak performance for Olympic Games or World Championships. When making this decision, coaches and athletes should reflect carefully on the potential impact the race may have on the rest of the competition season. Male athletes, in particular, may wish to consider foregoing Tour de Ski in an Olympic year. However, if the decision is made to participate, careful consideration should be given regarding how best to train in the weeks and days before and after the race, in order to prevent maladaptive outcomes and instead turn the event into a beneficial component of the athlete's championship preparation. 


\section{REFERENCES}

1. BAJ Z, KANTORSKI J, MAJEWSKA E, ZEMAN K, POKOCA L, FORNALCZYK E, TCHORZEWSKI H, SULOWSKA Z \& LEWICKI R. Immunological status of competitive cyclists before and after the training season. Int J Sports Med 1994: 15(06): 319-324.

2. BANISTER EW \& CALVERT TW. Planning for future performance: implications for long term training. Can J Appl Sport Sci 1980: 5(3): 170-176.

3. BOX, GEP \& COX DR. An analysis of transformations. J R Stat Soc Series B 1964: 26: 211-252.

4. BILLAT V, DEMARLE A, SLAWINSKI J, PAIVA M \& KORALSZTEIN JP. Physical and training characteristics of top-class marathon runners. Med Sci Sports Exerc 2001: 33: 2089-2097.

5. BILLAT V, LEPRETRE PM, HEUGAS AM, LAURENCE MH, SALIM D \& KORALSZTEIN JP. Training and bioenergetic characteristics in elite male and female Kenyan runners. Med Sci Sports Exerc 2003: 35: 297-304.

6. COUTTS AJ, REABURN P, PIVA TJ \& ROWSELL GJ. Monitoring for overreaching in rugby league players. Eur J Appl Physiol 2007: 99(3), 313-324.

7. ENGEBRETSEN L, STEFFEN K, ALONSO JM, AUBRY M, DVORAK J, JUNGE A, MEEUWISSE W, MOUNTJOY M, RENSTRÖM P \& WILKINSON M. Sports injuries and illnesses during the Winter Olympic Games 2010. Br J Sports Med 2010: 44 (11): 772-780.

8. ENGEBRETSEN L, SOLIGARD T, STEFFEN K, ALONSO JM, AUBRY M, BUDGETT R, DVORAK J, JEGATHESAN M, MEEUWISSE WH, MOUNTJOY M, PALMER-GREEN D, VANHEGAN I. \& RENSTRÖM PA. Sports injuries and illnesses during the London Summer Olympic Games 2012. Br J Sports Med 2013: 47(7): 407-414.

9. ENGLER RJ, NELSON MR, KLOTE MM, VANRADEN MJ, HUANG CY, COX NJ, KLIMOV A, KEITEL WA, NICHOL KL, CARR WW \& TREANOR JJ. Half- vs full-dose trivalent inactivated influenza vaccine (2004-2005): age, dose, and sex effects on immune responses. Archives of Internal Medicine 2008: 168: 2405-2414. 
10. FISKERSTRAND Â \& SEILER KS. Training and performance characteristics among Norwegian International Rowers 1970-2001. Scand J Med Sci Sports 2004: 14: 303-310.

11. FRICKER PA, PYNE DB, SAUNDERS PU, COX AJ, GLEESON M \& TELFORD RD. Influence of training loads on patterns of illness in elite distance runners. Clin J Sport Med 2005: 15: 246-52.

12. FURMAN D, HEJBLUM BP, SIMON N, JOJIC V, DEKKER CL, THIÉBAUT R, TIBSHIRANI RJ \& DAVIS MM. Systems analysis of sex differences reveals an immunosuppressive role for testosterone in the response to influenza vaccination. Proc Natl Acad Sci 2014: 111(2): 869-874.

13. GAO J. A Study on Pre-Game Training Characteristics of Chinese Elite Swimmers. J Beijing Sport Univ 2008: 31: 832-834.

14. GLEESON M., BISHOP N, OLIVEIRA M. \& TAULER P. Influence of training load on upper respiratory tract infection incidence and antigenstimulated cytokine production. Scand J Med Sci Sports 2011: 23(4): 451-457.

15. GLEESON M, MCDONALD WA, CRIPPS AW, PYNE DB, CLANCY RL \& FRICKER PA. The effect on immunity of long-term intensive training in elite swimmers. Clin Exp Immunol 1995: 102(1): 210-216.

16. GUELLICH A, SEILER S, EMRICH E. Training Methods and Intensity Distribution of Young World-Class Rowers. Int J Sports Physiol Perform 2009: 4: $448-460$.

17. HALSON SL, LANCASTER GI, JEUKENDRUP AE \& GLEESON M. Immunological responses to overreaching in cyclists. Med Sci Sports Exerc 2003: 35(5): 854-861.

18. HE CS, BISHOP NC, HANDZLIK MK, MUHAMAD AS \& GLEESON M. Sex differences in upper respiratory symptoms prevalence and oral-respiratory mucosal immunity in endurance athletes. Exerc Immunol Rev 2014: 20: 8-22.

19. LANCASTER GI, HALSON SL, KHAN Q, DRYSDALE P, WALLACE F, JEUKENDRUP AE, DRAYSON MT \& GLEESON M. Effects of acute exhaustive exercise and chronic exercise training on type 1 and type $2 \mathrm{~T}$ lymphocytes. Exerc Immunol Rev 2004: 10(91): 106. 
20. MACKINNON LT \& HOOPER S. Mucosal (secretory) immune-system responses to exercise of varying intensity and during overtraining. Int J Sports Med 1994: 15(S 3): S179-S183.

21. MATTHEWS A, PYNE D, SAUNDERS P, FALLON K \& FRICKER P. A self-reported questionnaire for quantifying illness symptoms in elite athletes. Open Access J Sports Med 2010: 1: 15.

22. MEEUSEN R, DUCLOS M, GLEESON M, RIETJENS G, STEINACKER J \& URHAUSEN A. Prevention, diagnosis and treatment of the overtraining syndrome: ECSS Position Statement ‘Task Force’. Eur J Sport Sci 2006: 6(01): $1-14$.

23. MEYER T, FAUDE O, URHAUSEN A, SCHARHAG J \& KINDERMANN $W$. Different effects of two regeneration regimens on immunological parameters in cyclists. Med Sci Sports Exerc 2004: 36 (10): 1743-1749.

24. MOREIRA A, DELGADO L, MOREIRA P \& HAAHTELA T. Does exercise increase the risk of upper respiratory tract infections? Br Med Bull 2009: 90: 111-31.

25. MORGADO JM, RAMA L, SILVA I, INACIO MDJ, HENRIQUES A, LARANJEIRA P, PEDREIRO S, ROSADO F, ALVES F, GLEESON M, PAIS ML, PAIVA A \& TEIXEIRA AM. Cytokine production by monocytes, neutrophils, and dendritic cells is hampered by long-term intensive training in elite swimmers. Eur J Appl Physiol 2012: 112(2): 471-482.

26. NIEMAN DC. Exercise, upper respiratory tract infection, and the immune system. Med Sci Sports Exerc 1994: 26: 128-139.

27. NIEMAN DC. Is infection risk linked to exercise workload? Med Sci Sports Exerc 2000: 32: S406-S411.

28. NEAL CM, HUNTER AM, GALLOWAY SD. A 6-month analysis of trainingintensity distribution and physiological adaptation in Ironman triathletes. $\mathrm{J}$ Sports Sci 2011: 29: 1515-23.

29. REESER JC, WILLICK S \& ELSTAD M. Medical services provided the Olympic Village polyclinic during the 2002 Salt Lake City Winter Games. Wisc Med J 2003: 102: 20-5. 
30. ROBSON-ANSLEY PJ, BLANNIN A \& GLEESON M. Elevated plasma interleukin-6 levels in trained male triathletes following an acute period of intense interval training. Eur J Appl Physiol 2007: 99(4): 353-360.

31. SCHUMACHER OY \& MUELLER P. The 4000-m team pursuit cycling world record: Theoretical and practical aspects. Med Sci Sports Exerc 2002: 34: 1029-1036.

32. SPENCE L, BROWN WJ, PYNE DB, NISSEN MD, SLOOTS TP, MCCORMACK JG, LOCKE AS \& FRICKER PA. Incidence, etiology, and symptomatology of upper respiratory illness in elite athletes. Med Sci Sports Exerc 2007: 39(4): 577.

33. SYLTA O, TØNNESSEN E \& SEILER S. Do elite endurance athletes report their training accurately? Int J Sports Physiol Perform 2014: 9: 85-92.

34. TØNNESSEN E, SYLTA Ø, HAUGEN TA, HEM E, SVENDSEN IS \& SEILER S. The Road to Gold: Training and Peaking Characteristics in the Year Prior to a Gold Medal Endurance Performance. PloS one 2014: 9(7): e101796.

35. TØNNESSEN E, SVENDSEN IS, RØNNESTAD BR, HISDAL J, HAUGEN TA \& SEILER S. The Annual Training Periodization of Eight World Champions in Orienteering. Int J Sports Physiol Perform 2014 (In Press).

36. ZAPICO AG, CALDERÓN FJ, BENITO PJ, GONZÁLEZ CB, PARISI A, PIGOZZI F \& DI SALVO V. Evolution of physiological and haematological parameters with training load in elite male road cyclists: A longitudinal study. J Sports Med Phys Fitness 2007: 47: 191-196. 


\section{Figure Legends}

Figure 1: Average daily TRIMP score for 6 weeks before Tour de Ski, during Tour de Ski, and 6 weeks after Tour de Ski.

\#significantly different from 6 weeks before TDS for both men and women $(p<0.01)$; * significantly different from men $(p<0.01)$. Data are Mean $+S D$.

Figure 2: Total race distance (A) and total competition time (B) in men's and women's Tour de Ski. * Significantly different from men $(p<0.001)$. Data are Mean $+S D$.

Figure 3: Percentage of male and female athletes who became ill during or within 10 days after Tour de Ski, or during the same time period for the control group.

TDS = took part in Tour de Ski

CON = did not take part in Tour de Ski

Figure 4: Average placing achieved by male athletes in international competition (World Cup/Olympic Games/World Championships) 6 weeks before and 6 weeks after Tour de Ski.

Data are geometric mean $\pm 95 \%$ CI.

TDS = took part in Tour de Ski, CON = did not take part in Tour de Ski

* Significantly different vs. 6weeks before TDS $(p=0.003)$. No change in CON.

Figure 5: Best placing achieved by male athletes in international competition (World Cup / Olympic Games / World Championships) 6 weeks before and 6 weeks after Tour de Ski.

Data are geometric mean $\pm 95 \%$ CI.

TDS = took part in Tour de Ski, CON = did not take part in Tour de Ski

* Significantly different vs. 6weeks before TDS $(p<0.001)$. No change in CON.

Figure 6: Placing in World Championships (WC) \& Olympic Games (OL) normalised as a percentage of each athlete's mean placing for the season (i.e. less than $100 \%=$ better than average performance). Data are mean $+S D$.

TDS = took part in Tour de Ski, CON = did not take part in Tour de Ski.

Significant interaction effect (Gender*TDS, $p=0.046$ ) 
Table 1: Characteristics of athletes included in the study at the time of the analysed season.

\begin{tabular}{ccc}
\hline & $\begin{array}{c}\text { Male } \\
(\mathrm{n}=63 \text { seasons })\end{array}$ & $\begin{array}{c}\text { Female } \\
(\mathrm{n}=52 \text { seasons })\end{array}$ \\
\hline Age $(\mathrm{yrs})$ & $24 \pm 3$ & $24 \pm 4$ \\
Body mass $(\mathrm{kg})$ & $76.0 \pm 6.1$ & $60.1 \pm 4.8$ \\
$\dot{V} \mathrm{O}_{2 \max }\left(\mathrm{ml} \cdot \mathrm{kg}^{-1} \cdot \mathrm{min}^{-1}\right)$ & $78.2 \pm 5.1$ & $70.6 \pm 5.2$ \\
$\dot{V} \mathrm{O}_{2 \max }\left(\mathrm{L} \cdot \mathrm{min}^{-1}\right)$ & $5.9 \pm 0.5$ & $4.2 \pm 0.4$ \\
Annual training volume (hrs) & $716 \pm 91$ & $816 \pm 103$ \\
Took part in Tour de Ski & $\mathrm{n}=17(27 \%)$ & $\mathrm{n}=25(48 \%)$ \\
\hline
\end{tabular}


Table 2. The 5-zone intensity scale used by athletes to classify their training

\begin{tabular}{cccc}
\hline $\begin{array}{c}\text { Intensity } \\
\text { Zone }\end{array}$ & $\begin{array}{c}\text { Typical blood } \\
\text { lactate }^{\mathbf{A}} \\
\left(\mathbf{m m o l} \cdot \mathbf{L}^{\mathbf{- 1}}\right)\end{array}$ & $\begin{array}{c}\text { Typical } \\
\text { Heart Rate } \\
\mathbf{( \% ~ m a x )}\end{array}$ & Binary model \\
\hline $\mathbf{5}$ & $>5.8$ & $>94$ & \\
$\mathbf{4}$ & $3.7-5.7$ & $89-93$ & HIT \\
$\mathbf{3}$ & $2.1-3.6$ & $84-88$ & \\
\hline $\mathbf{2}$ & $1.3-2.0$ & $74-83$ & LIT \\
$\mathbf{1}$ & $<1.2$ & $54-73$ & \\
\hline
\end{tabular}

${ }^{\text {A }}$ Measured with Lactate Pro LT-1710. Reference values presented are derived from the average self-reported zone-cut offs of 29 elite XC-skiers (Tønnessen et al., 2014), and individual adjustments are necessary. HIT: High-intensity training, LIT: Low-intensity training. 
Figure 1

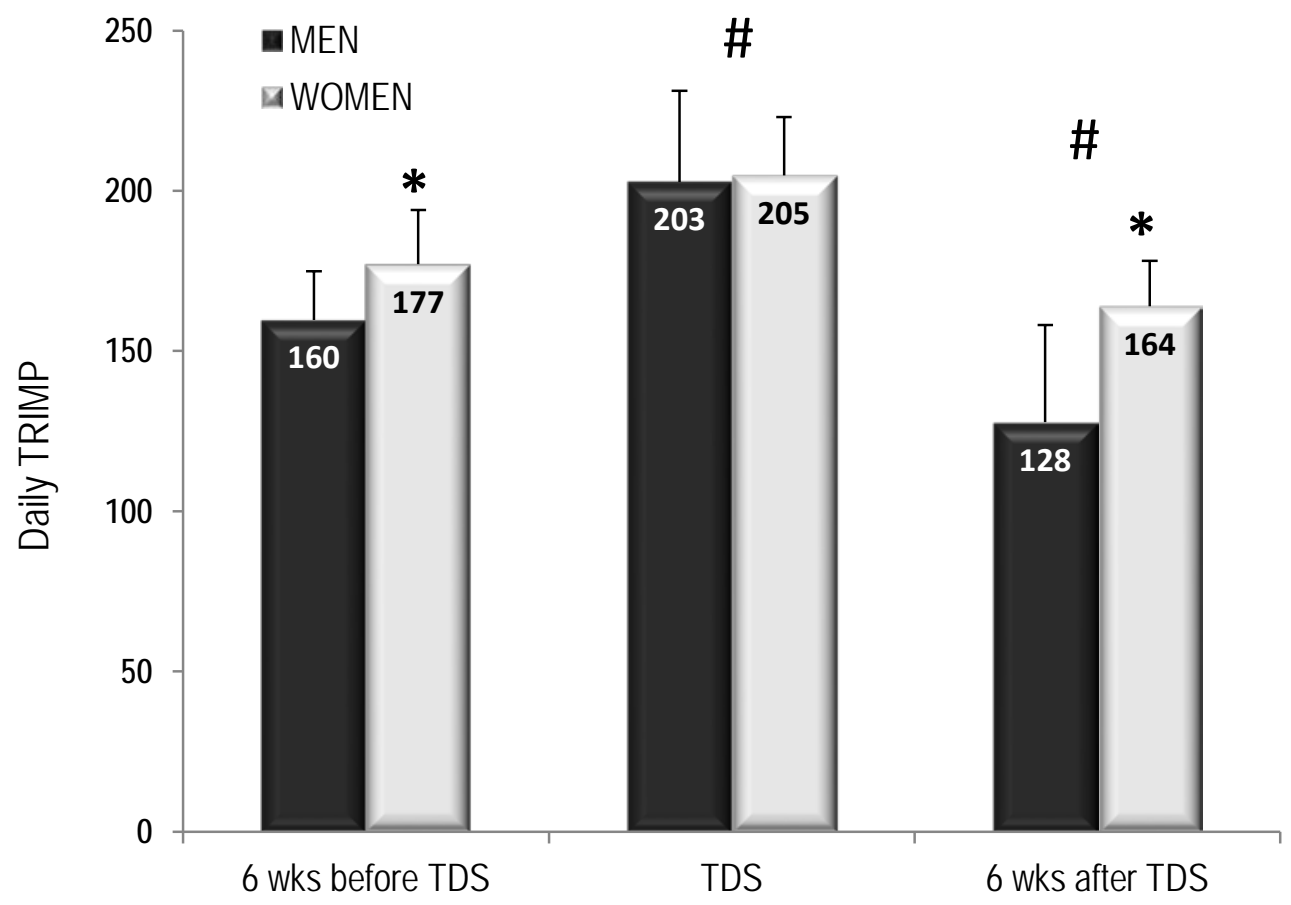


Figure 2
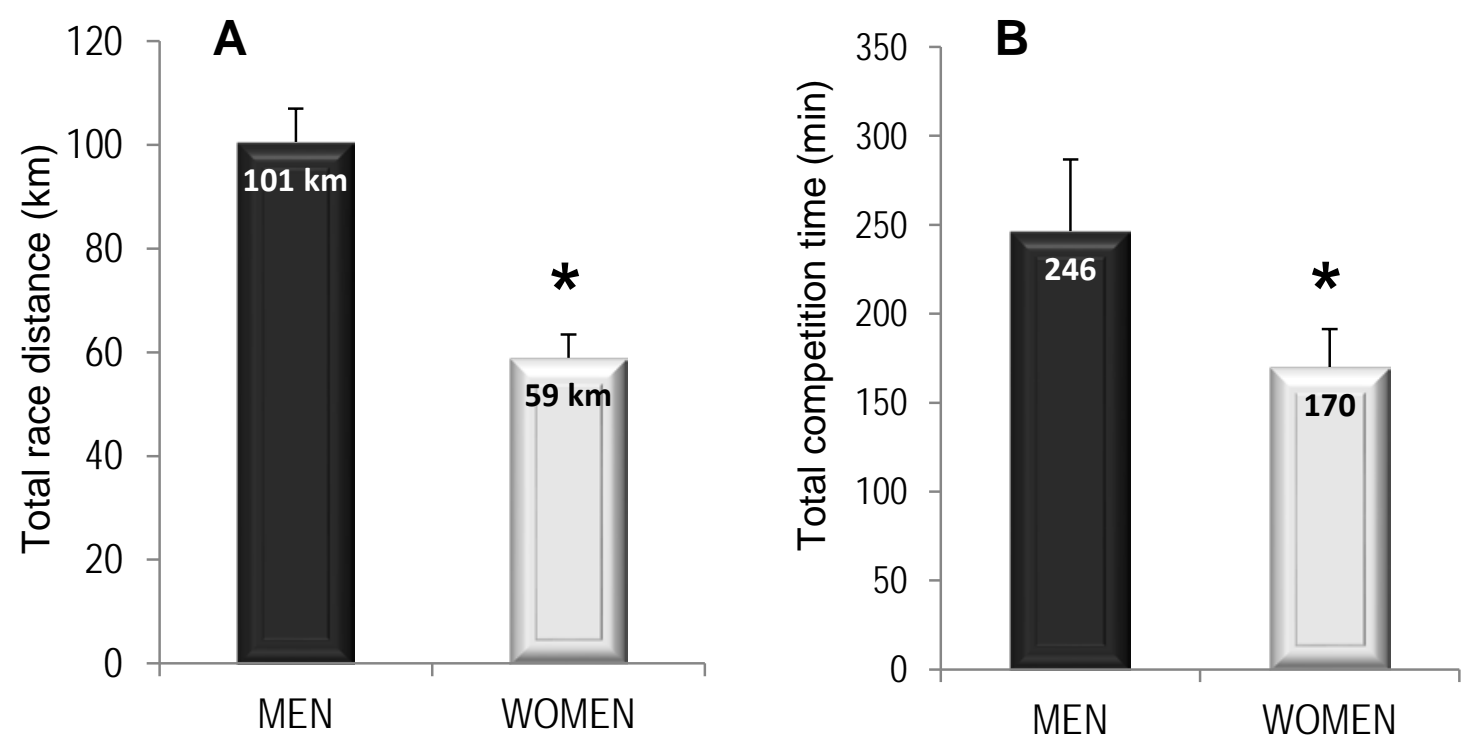
Figure 3

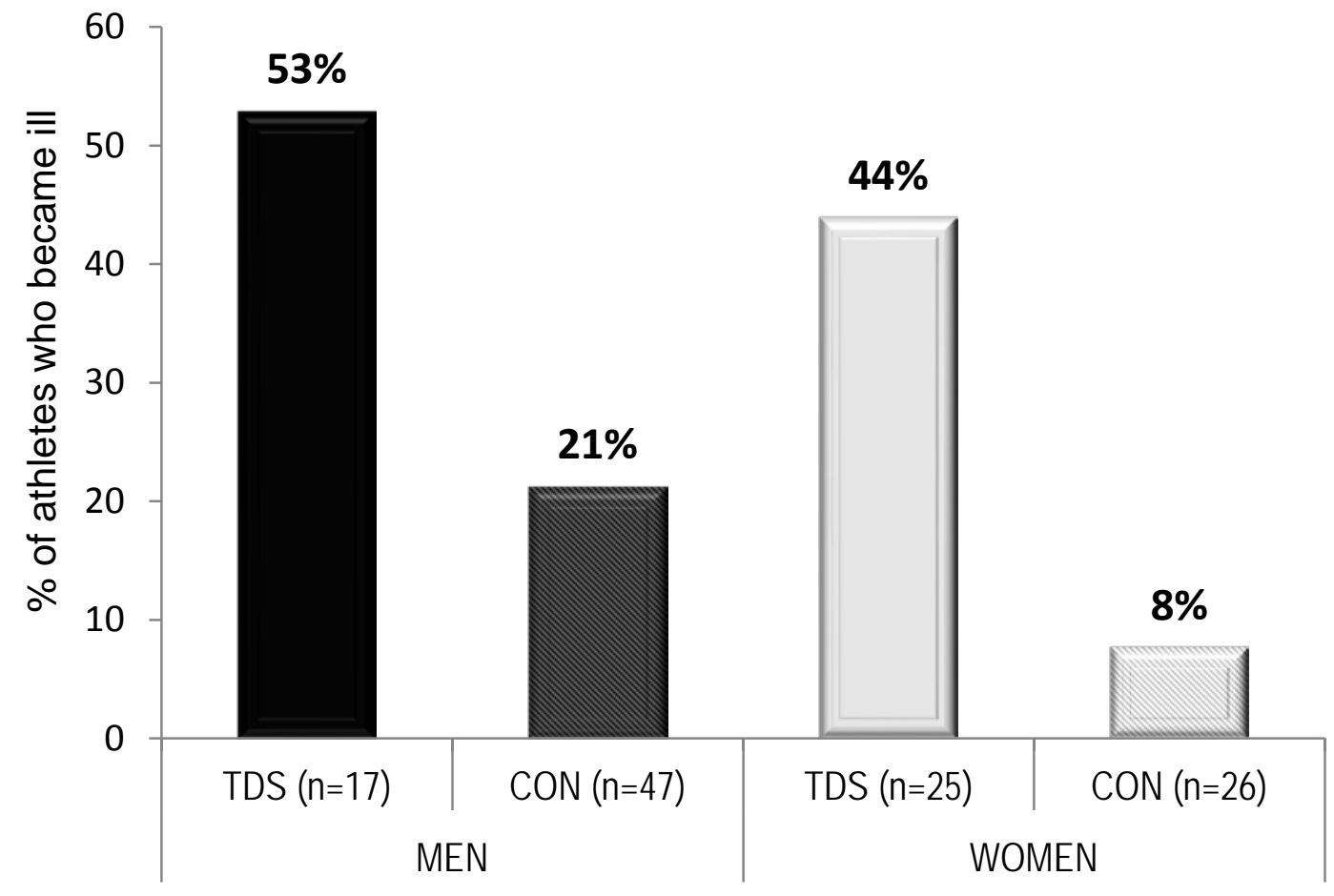


Figure 4

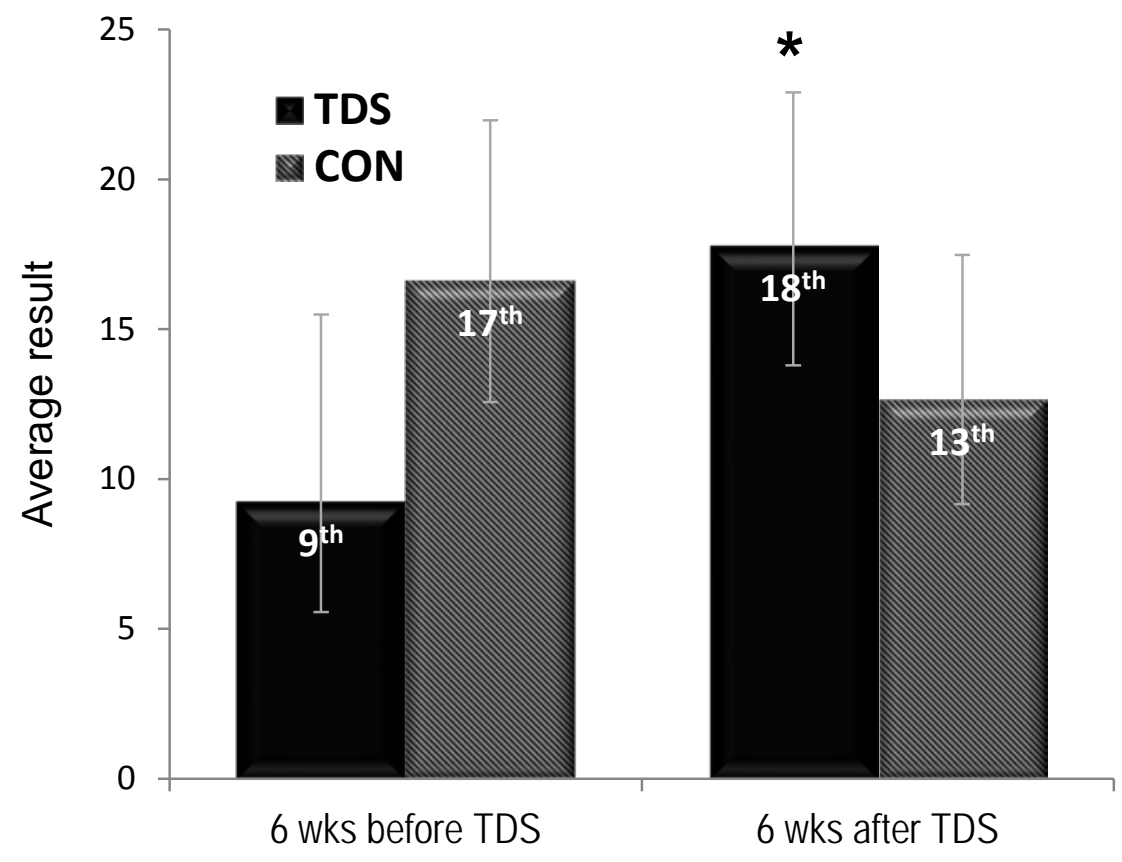


Figure 5

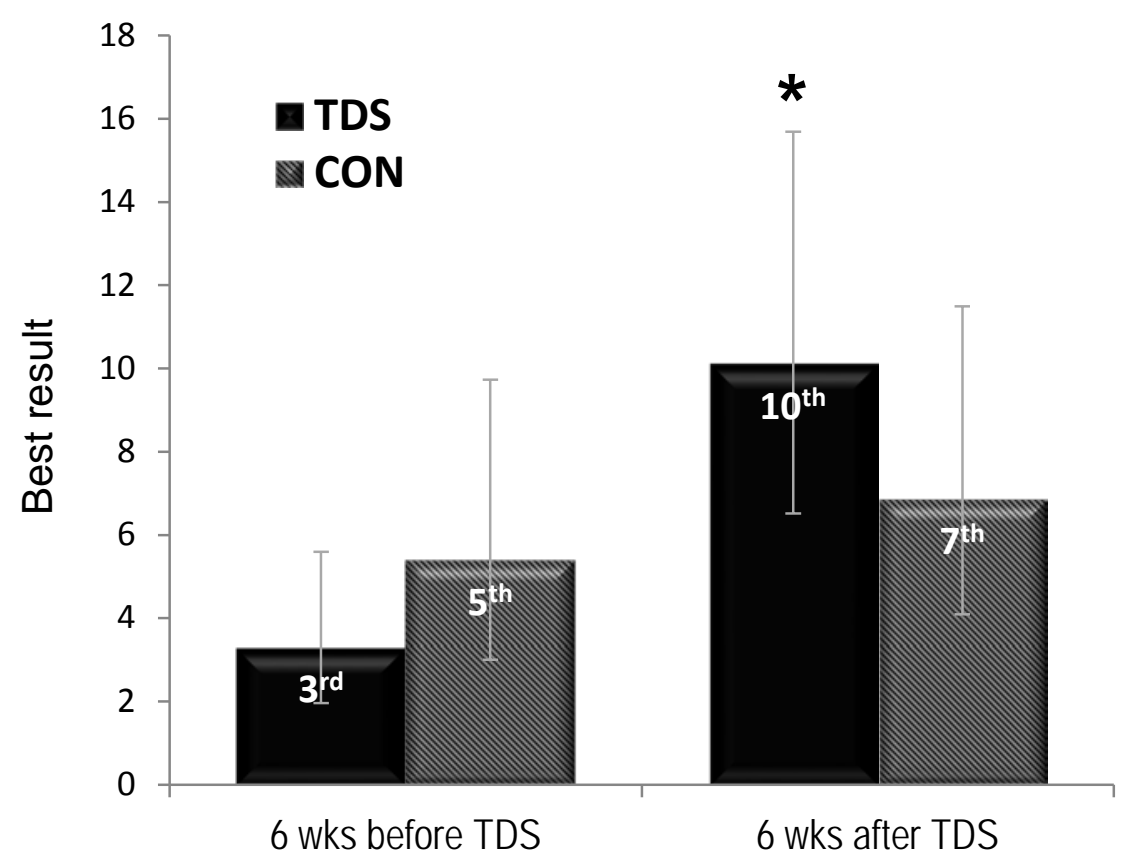


Figure 6

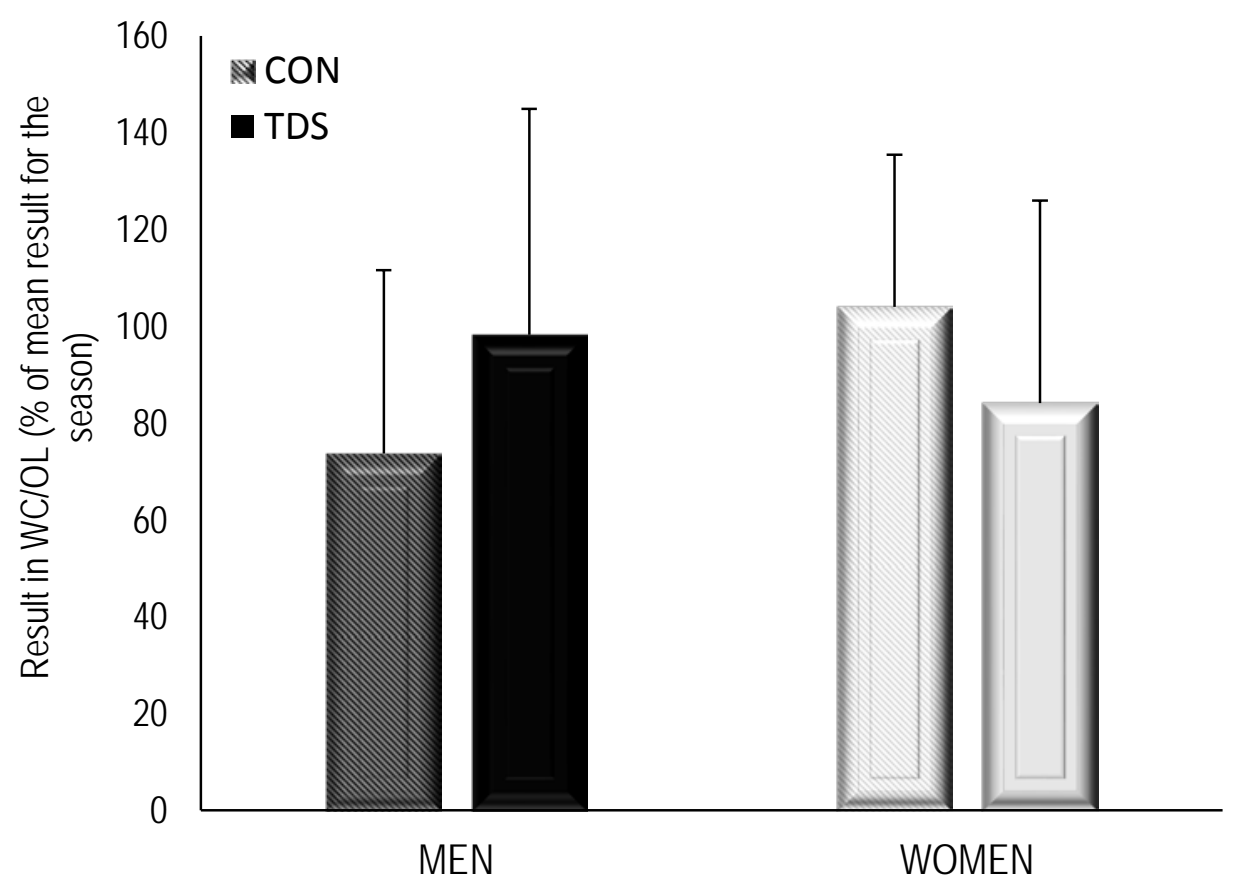

